\title{
CORRELATING SPIROMETRIC PARAMETERS WITH BREATH-HOLDING TIME AND MAXIMUM CHEST EXPANSION IN HEALTHY YOUNG ADULTS
}

\author{
Amatya $M^{1}$, Pun $D B^{2}$
}

${ }^{1}$ Department of Physiology, Nepal Medical College Teaching Hospital, Attarkhel, Gokarneshwor-8, ${ }^{2}$ Department of

Physiology, Kantipur Dental College, Kathmandu, Nepal

\begin{abstract}
The spirometric measurements are very sensitive, accurate and reliable parameters, which have diagnostic as well as prognostic values. We aimed to find the reliability of two simple measurements, namely chest expansion and voluntary breath holding, which are often suggested as tools for screening and monitoring of respiratory diseases. A cross-sectional descriptive study was conducted on students of Nepal Medical College. Measurements of spirometry (forced vital capacity, FVC in liter; forced expiratory volume in first second, $\mathrm{FEV}_{1}$ in liter; and peak expiratory flow rate, PEF in liter per second), cirtometry (average of maximum chest expansion, CE in centimeter), and breath-holding time (maximum voluntary apnea at end-inspiration, MVAIT and maximum voluntary apnea at endexpiration, MVAET in second) were performed. Degrees of correlation (Pearson's r) were determined between different parameters; setting level of significance at $95 \%$. Total 308 students $(\mathrm{M}=164,53.25 \%$; $\mathrm{F}=144,46.75 \%$ ) participated. Owing to very highly significant differences between males and females, gender-separate correlations were determined. In males, CE correlation was very highly significant $(\mathrm{p}=0.000)$ with $\mathrm{FVC}$ and $\mathrm{FEV}_{1}$ but not with PEF. MVAET correlated significantly with FVC, $\mathrm{FEV}_{1}$ and PEF; MVAIT correlation was not significant with any parameters. In females, CE correlation was significant with FVC and FEV 1 but not with PEF; MVAET and MVAIT correlations were not significant with any of the parameters. In conclusion, the correlation of CE with different spirometric parameters is significant but not very strong $(0.3<\mathrm{r}<0.5)$. Also, gender differences exist. Therefore, using $\mathrm{CE}$ and breath-holding time may not be appropriate to assess respiratory ventilatory function.
\end{abstract}

\section{KEYWORDS}

Breath-holding time, cirtometry, spirometry

\section{CORRESPONDING AUTHOR}

Dr. Mrigendra Amatya,

Department of Physiology,

Nepal Medical College Teaching Hospital,

Attarkhel, Gokarneshwor-8, Kathmandu, Nepal

Email: amatyam01@gmail.com

ORCID ID: 0000-0002-0312-3220 


\section{INTRODUCTION}

Spirometry is commonly used means to assess lung ventilatory function in various diseases. Forced vital capacity (FVC), forced expiratory volume in first second $\left(\mathrm{FEV}_{1}\right)$, and peak expiratory flow (PEF) are some of the important spirometric parameters. Chest size and mobility, strength of respiratory muscles, and size of the airways are some of the important factors affecting spirometric findings. ${ }^{1,2,3}$

Chest expansion (CE) is defined as the difference between chest circumferences at maximal inhalation and maximal exhalation. ${ }^{4}$ Normal chest wall mobility is important for lung expansion and subsequent ventilation; thus measurement of $\mathrm{CE}$, that is cirtometry, is one of the simplest techniques to evaluate respiratory function. CE demonstrates high inter-rater and intra-rater reliability. ${ }^{5,6}$ Its correlation with lung volumes and capacities is diverse, hence making its use as an alternate to spirometry is arguable. ${ }^{7}$

The other measurement, breath holding time (BHT) or voluntary apnea time is determined as the breaking point of voluntary breath hold which occurs when urge to resume breathing exceeds the will to hold the breath. ${ }^{8,9}$ It can be determined for maximal voluntary apnea expiratory or inspiratory time (MVAET, MVAIT). BHT has been found to be well correlated with $\mathrm{FEV}_{1}$ and magnitude of dyspnea in patients. ${ }^{10,11}$

Owing to their simplicity and cost effectiveness, the $\mathrm{CE}$ and BHT have been suggested as reasonable alternatives to spirometry in resource-poor settings with the advantage of independence from technician and machine. ${ }^{12,13}$ This study aims to verify this claim.

\section{MATERIALS AND METHODS}

The study was conducted on the first and second year medical and dental students of Nepal Medical College Teaching Hospital (NMCTH), from November 2013 to October 2014. Students were asked to abstain from strenous physical activity and large meal for a day and to wear comfortable clothes on the day of the test. Smokers, those on regular exercises, having common cold and other respiratory disorders, oral and facial pain, and musculoskeletal problems of the chest wall were excluded from the study. Ethical clearance was obtained from the Institutional Review Committee of the NMCTH. Informed written consent was obtained from participants.

CE was performed with the help of the tailor's inelastic measuring tape with the subject standing erect and hands on the waist. Upper thoracic level was marked at the fifth thoracic spinous process at the back and the third intercostal space at the mid-clavicular line in the front; the lower thoracic level was marked at the tenth thoracic spinous process at the back and the tip of the xiphoid process in the front. Thoracic circumferences were measured in maximum inspiration and maximum expiration at both levels, three times with five minutes rest in between, and the best values were taken (highest for inspiration and lowest for expiration). CE (in centimeter) was calculated as the difference between maximum (end-inspiratory) and minimum (end-expiratory) thoracic circumferences. ${ }^{14}$

Breath-holding time (BHT) was also calculated. For maximal voluntary apnea inspiratory time (MVAIT in second), subjects were asked to take three deep breaths and to hold breath at last end-inspiration, then counting to breaking point. For maximal voluntary apnea expiratory time (MVAET in second), subjects were asked to take three deep breaths and to hold breath at last endexpiration till breaking point. Each maneuver was repeated three times and the best (highest) values were considered. ${ }^{15}$

Forced spirometry was performed in computerized spirometer (Spiro Excel Machine Spirometer, Medicaid System, Chandigarh, India, 2003). Spirometer was prepared, calibrated, and subject was properly instructed. In comforatble standing position, the subject inspired maximum deeply, then expelled as much air as he/she can with maximum effort into the mouthpiece (nose clip-closed). Three satisfactory readings were taken, allowing 5 minutes rest between efforts, and the best value was considered. ${ }^{1}$ Forced vital capacity (FVC in liter), forced expiratory volume in first second ( $\mathrm{FEV}_{1}$ in liter), and peak expiratory flow rate (PEF in liter per second) were considered for comparisons and correlations.

The collected data was entered in Microsoft Excel worksheet and analysed with the SPSS version 16.0. Degrees of correlation between variables were determined by Pearson's correlation coefficient (r); level of significance was set at 95\% ( $p$ value 0.05 ).

\section{RESULTS}

Total 308 students participated in the study; the female and male populations differed significantly in age and anthropometric variables (Table 1).

Similarly, respiratory parameters were also significantly different between females and males (Table 2). Next, the correlation (Pearson correlation, r) between different parameters were detemined for female and male participants (Table 3). 
Table 1: Comparison of average of age and anthropometric variables of male and female participants compared

\begin{tabular}{lcccc|} 
Parameters & $\begin{array}{c}\text { Female, } \mathbf{n}=\mathbf{1 4 4} \\
(\mathbf{m e a n} \pm \mathbf{S D})\end{array}$ & $\begin{array}{c}\text { Male, } \mathbf{n}=\mathbf{1 6 4} \\
(\mathbf{m e a n} \pm \mathbf{S D})\end{array}$ & ANOVA (F) & P value \\
Age (years) & $19.1 \pm 1.1$ & $19.6 \pm 1.2$ & 15.6 & 0.000 \\
Height (cm) & $159.4 \pm 5.7$ & $172.5 \pm 6.6$ & 341.1 & 0.000 \\
Weight (kg) & $54.7 \pm 8.4$ & $65.5 \pm 10.8$ & 93.2 & 0.000 \\
BMI $\left(\mathbf{k g} / \mathbf{m}^{2}\right)$ & $21.5 \pm 3.3$ & $21.9 \pm 3.1$ & 1.4 & 0.237 \\
\hline
\end{tabular}

In either sex, CE was significantly correlated (positive correlation) with FVC and $\mathrm{FEV}_{1}$ but not with PEF; the correlations were highly significantin males. Expiratory voluntary apnea time (MVAET) correlated significantly (positive correlation) with all three spirometric parameters in males but not in females. The inspiratory voluntary apnea time (MVAIT) had no significant correlation with any of the spirometric parameters in either sex. Also, there was weak (not statistically significant) positive correlation between CE and BHT $(r<0.15$, p>0.05; not shown in table).

\section{DISCUSSION}

The spirometry as the tool of pulmonary function tests, in providing objective, quantifiable measures of lung function is established and widely used. ${ }^{16}$ Accurate and reliable results depend on accurate equipment, operator compentency, and cooperative patient, and its biggest limitation is the interpretation of results of poorly performed tests. ${ }^{17}$ Some simpler tools such as single parameter measurements (vital capacity), CE, BHT, exercise tolerance tests, and even smart phone based games have been tried. This study aimed to assess whether CE and BHT have strong correlations with select spirometric parameters to be useful as screening tools for respiratory health assessment. Such studies are scantily available in litearture search.

In this study, spirometry, cirtometry, and voluntary apnea times were determined in 308 young adults. Nepal et al (2014) reported spirometric evaluation in a similar populatioin of Nepalese medical students $(\mathrm{n}=174,103$ males and 71 females). While the age is similar, the spirometric values in their study are lower for males as well as

Table 2: Comparisons of BHT, cirtometry, and spirometric parameters between females and males

\begin{tabular}{|lcccc|} 
& Female, $\mathbf{n}=\mathbf{1 4 4}(\mathbf{m e a n} \pm \mathbf{S D})$ & Male, $\mathbf{n}=\mathbf{1 6 4}(\mathbf{m e a n} \pm \mathbf{S D})$ & ANOVA F & $\mathbf{p}$ value \\
MVAIT (sec) & $39.6 \pm 12.9$ & $54.5 \pm 40.8$ & 17.06 & 0.000 \\
MVAET (sec) & $25.6 \pm 8.6$ & $30.1 \pm 22.1$ & 4.89 & 0.028 \\
FVC (1) & $2.8 \pm 0.3$ & $4.2 \pm 0.5$ & 378.92 & 0.000 \\
FEV $_{\mathbf{1}}(\mathbf{l})$ & $2.5 \pm 0.3$ & $3.6 \pm 0.5$ & 333.14 & 0.000 \\
PEF (l/s) & $5.8 \pm 1.1$ & $9.3 \pm 1.4$ & 369.78 & 0.000 \\
CE (cm) & $5.6 \pm 1.4$ & $8.7 \pm 2.2$ & 180.98 & 0.000 \\
\hline
\end{tabular}

Table 3: Correlation of voluntary apnea time and chest expansion with spirometric parameters in females and males

\begin{tabular}{llccccccc}
\multirow{2}{*}{ Parameters } & Statistics & \multicolumn{3}{c}{ Female (n=144) } & \multicolumn{3}{c}{ Male (n=164) $^{*}$} \\
& & FVC & FEV $_{\mathbf{1}}$ & PEF & FVC & FEV $_{\mathbf{1}}$ & PEF \\
\multirow{2}{*}{ MVAIT } & Pearson correlation & 0.092 & 0.204 & 0.226 & -0.066 & -0.058 & -0.006 \\
& P value & 0.460 & 0.097 & 0.066 & 0.469 & 0.520 & 0.945 \\
\multirow{2}{*}{ MVAET } & Pearson correlation & 0.070 & 0.153 & 0.017 & 0.227 & 0.177 & 0.196 \\
& P value & 0.573 & 0.217 & 0.893 & 0.011 & 0.049 & 0.029 \\
CE & Pearson correlation & 0.357 & 0.288 & 0.138 & 0.448 & 0.380 & 0.145 \\
& P value & 0.002 & 0.015 & 0.249 & 0.000 & 0.000 & 0.074 \\
\hline
\end{tabular}


females compared to our findings. ${ }^{18}$ Closer values of FVC, $\mathrm{FEV}_{1}$, and PEF have been reported by Bandyopathyay et al (2013) in a group of 87 male university students in Kolkata, India. ${ }^{19}$ Studies conducted on wider range of age or on patients would find variable measurments. Reddy et al (2019) have reported higher FVC $(5.1 \pm 0.8 \mathrm{l})$ and $\mathrm{FEV}_{1}(5.1 \pm 0.6 \mathrm{l})$ values in an all male study $(\mathrm{n}=25$, mean age $=23.6 \pm 5.3$ years) ${ }^{13}$

Regarding CE, the mean CE of $8.72 \mathrm{~cm}$ in males in this study is considerably higher than the 5.6 $\mathrm{cm}$ reported by Reddy et al, which is closer to the CE of females in this study $(5.57 \pm 1.39 \mathrm{cms})$. Bockenhauer et al (2007), also reported a mean upper thoracic CE of $4.2 \pm 0.8 \mathrm{~cm}$, and suggested that cloth tape measurement of the thoracic excursion is a highly reliable procedure. ${ }^{4}$ Adedoyin et al (2012) reported mean upper thoracic CE of $3.5 \pm 1.6 \mathrm{cms}$ and $2.9 \pm 1.7 \mathrm{~cm}$ for males and females, respectively in an African population (age range 20-29 years). The mean CE is lower in patients of ankylosing spondylitis $(3.05 \pm 1.63$ $\mathrm{cms})^{20}$ and chronic obstructive pulmonary disease $(3.7 \pm 0.8 \mathrm{cms}) .{ }^{13,14}$ Fisher et al found a very strong correlation $(r=0.71, p<0.001)$ between CE and VC in the patients with ankylosing spondylitis. ${ }^{20}$ Reddy et al also found very strong correlation of $\mathrm{CE}$ at upper thoracic level with FVC $(r=0.678, p<0.001)$ and $\mathrm{FEV}_{1}(\mathrm{r}=0.595, \mathrm{p}<0.001)$ in healthy controls. ${ }^{13}$ The correlations in our study were weaker, and significantly strong only for males ( $\mathrm{FVC}$ and $\mathrm{FEV}_{1}$ ). In one study in COPD patients, chest wall mobility was found to be highly reliable and associated with inspiratory capacity, yet not found to infer pulmonary function to satisfactory level. ${ }^{7}$
Regarding BHT, Palaniyandi et al (2017) found strong correlations of BHT (end-inspiratory) with FVC, $\mathrm{FEV}_{1}$, and PEF ( $\mathrm{r}=0.552,0.560$, and 0.333; all $\mathrm{p}<0.001)$. They suggested BHT to be a reasonable alternative to spirometry in a resource-poor setting. ${ }^{21}$ Similarly, Aggarwal et al (2018) reported a mean end-inspiratory tidal BHT in second of $34.56 \pm 18.74$ in a mixed age and sex population of 100 healthy volunteers, which is different from our findings. ${ }^{12}$ Also, the correlation coefficients of 0.447 and 0.455 (both highly significant) were found with post-bronchodilator FVC and $\mathrm{FEV}_{1}$ respectively. On this basis, they recommended BHT as a reasonable non-technician, non-machine dependent alternative to spirometry. However, BHTs had weak correlations with spirometry in our study, only MVAET in males having significant correlation with FVC and $\mathrm{FEV}_{1}$.

In conclusion, our study found correlations having statistical significant strength of spirometry with chest expansion but not with breath holding time and gender differences were observed in all. This could be due to the difference in the mechanisms responsible for each parameter. The chest excursion is principally dependent on the chest wall mobility and muscular efforts. On the other hand, breath holding time is importantly and additionally governed by the chemoreceptor regulation of respiration which overrides the voluntary control. ${ }^{8}$ In pathologic conditions, these correlations would be less predictable, therefore making their use as an alternative of spirometry less reliable.

\section{REFERENCES}

1. Schlegelmilch RM, Kramme R. Pulmonary Function Testing. In: Kramme R, Horffman K-P, Pozos R, editors. Springer Handbook of Medical Technology. Springer 2011: 95-118.

2. Ruppel GL. What Is the Clinical Value of Lung Volumes? Respir Care 2012; 57: 26-38.

3. Calverley P. The clinical usefulness of spirometric information. Breathe 2009; 5: 214-20.

4. Bockenhauer SE, Chen H, Julliard KN, Weedon J. Measuring thoracic excursion: reliability of the cloth tape measure technique. J Am Osteopath Assoc 2007; 107: 191-6.

5. Sharma J, Senjyu H, Williams L. Comparison of Chest Expansion Measurement in Clients with Ankylosing Spondylitis and Healthy Individuals. $J$ Phys Ther Sci 2004; 15: 47-51.

6. Lanza F de C, Camargo AA de, Archija LRF, Selman JPaR, Malaguti C, Corso SD. Chest Wall Mobility Is Related to Respiratory Muscle Strength and Lung Volumes in Healthy Subjects. Respir Care 2013; 58: 2107-12.
7. Malaguti C, Rondelli RR, de Souza LM, Domingues M, Dal Corso S. Reliability of chest wall mobility and its correlation with pulmonary function in patients with chronic obstructive pulmonary disease. Respir Care 2009; 54: 1703-11.

8. Parkes MJ. Breath-holding and its breakpoint. Exp Physiol 2006; 91 :1-15.

9. Lindholm P, Lundgren CEG. The physiology and pathophysiology of human breath-hold diving. $J$ Appl Physiol 2009; 106: 284-92.

10. Taskar V, Clayton N, Atkins M, Shaheen Z, Stone P, Woodcock A. Breath-holding time in normal subjects, snorers, and sleep apnea patients. Chest 1995; 107: 959-62.

11. Viecili RB. Real-Time Measurement of Maximal Voluntary Breath-Holding Time in Patients with Obstructive Ventilatory Defects and Normal Controls. J Pulm Respir Med 2013; 2: 2-4.

12. Aggarwal V, Godbole G, Agawane S, Pophale H. Correlation of breath holding time with spirometry 
test - An alternative non technician dependent surrogate test for spirometry. MedPulse Int'l J Med 2018; 5: 69-73.

13. Reddy RS, Alahmari KA, Silvian PS, Ahmad IA, Kakarparthi VN, Rengaramanujam K. Reliability of Chest Wall Mobility and Its Correlation with Lung Functions in Healthy Nonsmokers, Healthy Smokers, and Patients with COPD. Can Respir J 2019; 2019: 1-11. http://doi.org/10.1155/2019/5175949

14. Adedoyin RA, Adeleke OE. Reference Values for Chest Expansion among Adult Residents in Ile-Ife. $J$ Yoga Phys Ther 2012; 2: 54-8.

15. Viecili RB, Silva DeR, Sanches PRS, Muller AF, Silva DP da, Barreto SSM. Real-Time Measurement of Maximal Voluntary Breath-Holding Time in Patients with Obstructive Ventilatory Defects and Normal Controls. J Pulm Respir Med 2013; 2: 2-4.

16. Crapo RO. Pulmonary function testing. $N$ Engl J Med 1994; 331: 25-30.
17. Richards JA. Office spirometry - Indications and limitations. South African Fam Pract 2006; 48: 4851.

18. Nepal GB, Das PKL, Bhaila A. Spirometric evaluation of pulmonary functions of medical students in Nepal. Asian J Med Sci 2014; 5: 82-6.

19. Bandyopadhyay A, Bhattacharjee I, Dalui R, Pal S. Pulmonary function studies of healthy nonsmoking male university students of Kolkata, India revisited. Malaysian J Med Sci 2013; 20: 17-25.

20. Fisher LR, Cawley MI, Holgate ST. Relation between chest expansion, pulmonary function, and exercise tolerance in patients with ankylosing spondylitis. Ann Rheum Dis 1990; 49: 921-5.

21. Palaniyandi AK, Natarajan M, Chockalingam A, Karthick R, Professor A, Author C. Even a single breath counts. IOSR J Dent Med Sci 2017; 16: 70-2. 